\title{
Experimental Calibration of an Arsenic-in-Apatite Oxybarometer
}

\author{
BRYAN J. MACIAG ${ }^{1}$ JAMES M. BRENAN $^{1}$
}

${ }^{1}$ Department of Earth and Environmental Science, Dalhousie University, 1459 Oxford Street, Halifax, Nova Scotia,

Canada; Bmaciag@dal.ca

Spectroscopic studies of silicate melts have shown that both the trivalent and pentavalent forms of arsenic are stable, with the latter becoming more abundant with increasing oxygen fugacity $\left(f \mathrm{O}_{2}\right)$. As As ${ }^{5+}$ substitutes isovalently for $\mathrm{P}^{5+}$, it is expected that the partitioning of arsenic into phosphate minerals, such as apatite, will increase with increasing $\mathrm{fO}_{2}$. Hence, the potential exists to develop an arsenic-in-apatite oxybarometer applicable to apatite saturated magmas. Experiments are in progress to calibrate this oxybarometer with a specific emphasis on iron-poor felsic compositions. We used a piston-cylinder apparatus to synthesize a series of water-saturated arsenic-bearing glasses with coexisting apatites at $1000^{\circ} \mathrm{C}$ and $0.75 \mathrm{GPa}$. Glass compositions employed were iron-free rhyolites that ranged from peraluminous to peralkaline. We controlled the $f_{2}$ of the experiments by using either internal $\mathrm{Ru}-\mathrm{RuO}_{2}$ and $\mathrm{C}-\mathrm{CO}_{2}$ buffers, or by a double-capsule technique with Ni-NiO, Re$\mathrm{ReO}_{2}$, MnO- $\mathrm{Mn}_{2} \mathrm{O}_{3}$, or $\mathrm{Fe}_{2} \mathrm{O}_{3}-\mathrm{Fe}_{3} \mathrm{O}_{4}$ solid buffers. Runproduct phases were analyzed by laser ablation inductively coupled plasma mass spectrometry, and electron microprobe analysis. Select glasses were also analyzed by $\mathrm{x}$-ray absorption near-edge structures to determine the melt speciation of arsenic. Results from the experiments using the peralkaline composition indicate that the apatite/melt partition coefficient for arsenic increases from $<0.3$ at FMQ -1.0 to 7.4 at FMQ +5.9. Additional results at FMQ +7.5, show that partitioning of arsenic into apatite changes as a function melt composition, with the partition coefficient increasing from 2.6 for the peraluminous composition to 126 when the melt is peralkaline. Based on the difference between the most oxidized and most reduced apatite/melt partition coefficients for arsenic, an oxybarometer can be generated over the range of FMQ +2 to FMQ +10 in peralkaline felsic melts. Additionally, the variation in the apatite/melt partitioning with respect to melt composition and $f_{2}$ offers an explanation for some of the variation of arsenic in naturally occurring magmatic apatites, without the need to invoke an arsenic enriched sedimentary source. 